\title{
Modificaciones producidas en las proteínas alimentarias por su interacción con lípidos peroxidados. II. Mecanismos conocidos de la interacción lípido (oxidado) - proteína
}

\author{
Por F. J. Hidalgo, R. Zamora y M. Alaiz \\ Instituto de la Grasa y sus Derivados. C. S. I. C. \\ Avda. Padre García Tejero, 4. 41012-Sevilla.
}

RESUMEN

Modificaciones producidas en las proteinas alimentarias por su interacción con lípidos peroxidados. II. Mecanismos conocidos de la interacción lípido (oxidado)-proteína

Esta parte describe cómo las proteinas alimentarias son modificadas por lipidos oxigenados describiendo los distintos mecanismos conocidos: interacciones hidrofóbicas, reacciones radicalarias y formación de productos covalentes con los productos secundarios de oxidación lipídica.

PALABRAS-CLAVE: Alimento - Compuesto fluorescente - Información (articulo) - Interacción hidrofóbica - Interacción Ilpido (oxidado) proteina.

\section{SUMMARY}

Modifications produced in food proteins following interactions with oxidizing lipids. II. Mechanisms of oxidizing lipid-protein interactions

This part rewiews the mechanisms of oxidizing lipid-protein interactions. Hydrophobic interactions, radical reactions and formation of covalent compounds with secondary products of lipid oxidation are described.

KEY-WORDS: Fluorescent compound - Food - Hydrophobic interaction - Information (paper) - Oxidizing lipid - protein interactions.

\section{INTRODUCCION}

La parte I de esta serie (1) abordó el estudio de los mecanismos por el que los ácidos grasos son oxidados, centrándose especialmente en el número y variedad de los productos obtenidos. En un alimento existen diversos ácidos grasos que además están en contacto con material no lipídico. Todo esto hace que la reacción de oxidación lipídica se complique y el número de posibles productos se eleve hasta una cifra difícil de determinar. Por esta razón, el estudio de la degradación de los alimentos proteicos por lípidos peroxidados ha sido abordado a dos niveles. En primer lugar se han llevado a cabo estudios en sistemas modelo para tratar de averiguar cómo tenían lugar estas reacciones para, posteriormente, extrapolar los resultados a sistemas más complejos; $y$, en segundo lugar, se han llevado a cabo experiencias sobre alimen- tos con vista, sobre todo, a evaluar la importancia de estas reacciones desde un punto de vista toxicológico y nutricional.

El objetivo de esta segunda parte es el estudio a nivel molecular de cómo, a consecuencia de su interacción con lípidos peroxidados, se producen cambios en las proteínas y cómo estos cambios afectan a las características de las mismas. El efecto sobre las características nutricionales y toxicológicas de los alimentos será abordado en la parte III de este estudio.

Cuando una muestra de ovoalbúmina fue finamente pulverizada e incubada con linoleato de etilo oxidado a $60^{\circ} \mathrm{C}$ el grupo de Pokorny observó los siguientes cambios (2): a) en un primer estadío se formaron lipoproteínas enlazadas por puentes de hidrógeno que pasaron por un máximo para decrecer posteriormente y alcanzar una concentración prácticamente constante en el último paso de la reacción, y b) los lípidos enlazados covalentemente se formaron en un estadío siguiente a la descomposición de las lipoproteínas. Esto parece indicar que en estas reacciones se producen dos tipos de mecanismos. Hay un primer estadío que consiste en la formación de complejos no covalentes con el hidroperóxido lipídico o sus productos de descomposición que, de alguna manera, facilita la interacción entre los distintos grupos reactivos de lípidos y proteínas para dar lugar, en un paso posterior, a compuestos covalentes.

Esta formación de compuestos covalentes no es, sin embargo, uniforme en el sentido de que todos los aminoácidos reaccionan con los mismos compuestos de oxidación lipídica. Cuando el grupo de Hurrell (3) (4) incubó una mezcla de proteínas del suero bovino con linolenato de metilo observó que la metionina era más rápidamente transformada que la lisina, de acuerdo con los mecanismos de transformación que habían sido propuestos para estos aminoácidos, en los que la metionina reaccionaba mayoritariamente con los hidroperóxidos mientras que la lisina lo hacía con sus productos de descomposición.

Así pues cuando una proteína interacciona con lípidos peroxidados existe la posibilidad bien de la formación de complejos no covalentes o bien de la formación de com- 
plejos covalentes. Esta formación de complejos covalentes puede a su vez ocurrir a través de reacciones radicalarias, con el hidroperóxido o los radicales que fueron descritos en la parte I, o bien a través de reacciones no radicalarias con los productos secundarios de oxidación lipídica.

\section{FORMACION DE COMPLEJOS NO COVALENTES}

Cuando las proteínas son expuestas a lípidos peroxidados, una gran proporción de los complejos lipídicos con las proteínas ocurren a través de asociaciones hidrofóbicas y/o puentes de hidrógeno (5). Este fenómeno es conocido desde muy antiguo (6-8) y su fuerza impulsora es el cambio termodinámicamente desfavorable en la estructura del agua que sigue a la adición de un soluto no polar en ella. Como resultado de esto las moléculas no polares en solución tienden a agruparse para que el área de contacto se minimize. La asociación hidrofóbica de moléculas no polares con proteínas procede de una manera similar. Las moléculas no polares tienden a agruparse en las regiones hidrofóbicas accesibles de las proteínas. La consecuencia de este proceso es que la extensión de la asociación hidrofóbica entre pequeñas moléculas no polares y proteínas es dependiente de la conformación de la proteína que afecta la disponibilidad de las regiones hidrofóbicas para la asociación. Este tipo de enlace ha sido muy estudiado en relación al enlace de "flavors" a proteínas por la importancia organoléptica de los mismos y su, a veces, difícil eliminación (9-11).

La fuerza del complejo lípido-proteína puede ser definida por una serie de pasos de extracción (12-15). Kanazawa et al., (15) usando un ácido graso radiactivo, pudieron observar cómo éste era extraído en los pasos consecutivos de extracción. Si estos complejos físicos son ignorados entonces se pueden malinterpretar los resultados. Así, por ejemplo, en este mismo trabajo de Kanazawa et al. (15), se puede apreciar que las pérdidas de aminoácidos tras la correspondiente hidrólisis de la proteína es dependiente del tipo de extracción al que se ha sometido la muestra incubada. La proteína que sólo había sido sometida a una extracción etérea sufrió severas pérdidas de aminoácidos pero aquella que fue sometida a una extracción exhaustiva tuvo unas pérdidas mínimas. Otro dato sobre este punto puede venir dado por la inactivación de enzimas causada por hidroperóxidos lipídicos. De acuerdo a Matsushita et al. (16) el ácido linoleico mismo fue a veces tan efectivo como su hidroperóxido en su capacidad para inhibir ciertas enzimas en un rango bastante amplio de condiciones. El enlace de ácidos grasos a las regiones hidrofóbicas de la enzima, más que a una reacción química, pudiera haber sido la responsable de la modificación de la actividad. Por el contrario, estos mismos autores encontraron que la singular activación de la pepsina en presencia del hidroperóxido del ácido linoleico no es producida en presencia sólo del ácido (17).

Aparte de los hidroperóxidos, los productos secundarios derivados de la degradación del hidroperóxido también se enlazan fácilmente a la proteína. A este respecto, los aldehídos son, quizás, los productos secundarios que han recibido mayor atención sin duda debido a la importancia que tienen en las características organolépticas de los alimentos aún a una concentración muy baja (18) (19). Estos compuestos enlazan a las proteínas tanto mediante interacciones hidrofóbicas (20) como electrostáticas (21) y covalentes, siendo éstas últimas las que serán consideradas más extensamente en este estudio porque son las que causan cambios permanentes en los alimentos.

\section{FORMACION DE COMPLEJOS COVALENTES}

\subsection{A través de reacciones radicalarias}

En este caso el proceso se inicia con la abstracción de un protón de la proteína que puede tener lugar sobre el carbono $\alpha$ (22). Estos radicales, que han sido identificados por RSE (23), podrían combinarse, con lo que se produciría entrecruzamiento entre las cadenas polipeptídicas o polimerización, lo que implicaría cambios en la textura y propiedades funcionales de los alimentos; podrían asimismo adicionarse a dobles enlaces, por una reacción análoga a las descritas en la parte I; o podrían finalmente reaccionar con oxígeno para producir un hidroperóxido proteínico hipotético que ha sido propuesto por Gardner (22) y que podría explicar distintos hechos que son observados en estas reacciones. La homólisis de este hidroperóxido produciría un radical alcoxi que podría a su vez sufrir una reacción de B-escisión análoga a la descrita para los radicales alcoxi lipídicos en la parte I. Esta reacción permitiría explicar el incremento en el contenido de grupos aminos libres en proteínas que han sido peroxidadas en sistemas carentes de agua así como escisiones proteínicas observadas en las mismas (24).

Además del carbono en $\alpha$, las cadenas laterales de diferentes aminoácidos son susceptibles de ser dañados radicalariamente. Indudablemente, la diferente sensibilidad de las distintas cadenas al ataque radicalario es la explicación de la selectibilidad que existe en la peroxidación a ciertos aminoácidos. Generalmente los aminoácidos más sensibles a ataques radicalarios son: cisteína/cistina, metionina, triptófano, histidina, lisina y tirosina.

La degradación de cisteína probablemente procede via un tioradical por una abstracción del hidrógeno del grupo tiol. Fuertes señales de azufre radicalario han sido observadas por RSE en una mezcla de cisteína más linoleato de metilo peroxidado demostrando la susceptibilidad del tiol a los radicales. Cistina, varios óxidos de cisteína/cistina (25-29), alanina y $\mathrm{SH}_{2}(26)$ han sido encontrados como productos de la reacción.

Nuestro grupo ha encontrado que la dimerización de la proteína via radicales tiólicos transcurre más rápidamente que la dimerización carbono-carbono cuando se parte de una mezcla de B-lactoglobulina y 13-hidroperóxido del ácido linoleico (30). Esto sugiere que este tipo de radicales se forma más fácilmente que los de carbono que fueron citados anteriormente.

Cuando la reacción entre cisteína e hidroperóxido del 
ácido linoleico se lleva a cabo en ausencia de $\mathrm{O}_{2}$, Gardner encontró que la reacción evolucionaba de muy distinta forma. En vez de los óxidos de cisteína/cistina o la dimerización, en la reacción fueron identificados aductos lípido-aminoácidos (31) (32). El mecanismo propuesto (22) implica un radical epóxido, que proviene de un reordenamiento de un radical alcoxi, y que puede reaccionar con un radical tioalcoxi para dar una epoxiencisteína que ha sido aislada (22). En un solvente prótico el epóxido sufre solvólisis con ayuda anquimérica del grupo tioéter para dar lugar al producto final encontrado. Esta reacción podría ocurrir en las proteínas lo que implicaría un entrecruzamiento de este tipo entre lípidos y proteínas. No obstante, hoy en día no hay datos que puedan apoyar esta hipótesis.

El residuo de metionina es muy sensible a la oxidación pasando a metionina sulfóxido en presencia de linoleato de metilo peroxidante (33) o aceite peroxidante (34). Esto ilustra de alguna manera la facilidad de la iniciación radicalaria en los sustituyentes azufrados. El paso a metionina sulfona no es, en cambio, observado con lípidos peroxidantes. Este último compuesto es obtenido cuando la proteína es puesta en contacto con oxidantes muy fuertes del tipo del ácido perfórmico. Es importante la diferencia entre ambos derivados porque, como se verá posteriormente, la metionina sulfóxido es asimilada por el organismo como si fuera metionina, mientras que la sulfona no puede ser utilizada.

La degradación del triptófano por linoleato de metilo peroxidante ha sido estudiada por el grupo de Karel (35). Ellos postularon que el paso inicial era una adición radicalaria de un radical alcoxi lipídico al anillo de indol; sin embargo, otros (36) (37) han demostrado que la reacción de un grupo hidroxi en el carbono 3 del anillo era intermedio en la oxidación de los derivados de indol con varios oxidantes. Este segundo camino parece ser más lógico de acuerdo con los productos encontrados en estas reacciones (22).

Cuando la histidina se hizo reaccionar con lípidos peroxidantes, aquella sufrió reacciones tanto en el carbono $\alpha$ como en la cadena de imidazol. La formación de los ácidos imidazol-láctico e imidazol-lacético evidencia un ataque al carbono $\alpha$. La degradación del anillo de imidazol fue puesta en evidencia con la formación de valina y ácido aspártico. Esta última reacción parece ser que es la que tiene mayor importancia en proteínas (22).

Los productos de degradación de la lisina causada por linoleato de metilo peroxidante (33) indican que se trata de una reacción radicalaria que tuvo lugar tanto en el carbono $\alpha$ como en la cadena lateral. De particular interés es un dímero aislado (ácido 2,11-diamino-1,12- dodecadioico) que podría explicar una forma de dimerización en proteínas. No obstante, como se discutirá posteriormente, las reacciones más importantes de la lisina ocurren sobre el grupo amino terminal con los productos secundarios de oxidación lipídica.

Finalmente la tirosina también se ha mostrado que puede ser degradada radicalariamente en presencia de una peroxidasa y agua oxigenada (38). El proceso parece ser que tiene lugar por abstracción de un protón sobre el grupo hidroxilo para dar lugar a un radical libre que es estabilizado por resonancia. La reacción de dos radicales de este tipo daría lugar a un compuesto dimérico. El estudio de la importancia que dicha reacción pudiera tener en presencia de lípidos peroxidantes es algo que todavía está por realizar.

La importancia relativa de todas estas reacciones va a venir determinada por la conformación de la proteína y el acceso que el lípido peroxidante tenga a las diferentes cadenas laterales de los aminoácidos.

Cuando se llevó a cabo el estudio de la reacción entre el hidroperóxido del ácido linoleico y la B-lactoglobulina (30), que es una proteína globular pequeña con tan sólo una cisteína y dos triptófanos y los tres situados en la superficie, la reacción produce primeramente la destrucción de los triptófanos y a continuación se produce la oxidación de la cisteína. Estos fueron los hechos más destacados, aunque no se estudiaron otros aminoácidos. La lisina, que sí fue estudiada, parece ser que fue degradada por los productos secundarios de oxidación lipídica.

Por su parte, el grupo de Hurrel (3), estudiando el sistema proteína del suero bovino/linolenato de metilo, encontró que en un primer paso los aminoácidos oxidados eran cisteína y metionina para pasar a reaccionar posteriormente la lisina con los productos secundarios de oxidación. Ellos también encontraron pérdidas considerables de triptófano e histidina aunque no pudieron precisar si éstas eran debidas a reacciones radicalarias o con productos secundarios de oxidación lipídica.

Estos datos junto con los que se han venido comentando anteriormente indican que los aminoácidos que soportan mejor el radical libre son los azufrados que se oxidan con facilidad dependiendo siempre del acceso que tengan los lípidos a los mismos. Los otros aminoácidos que pueden sufrir reacciones radicalarias son los heterocíclicos, quizás por la contribución de los heteroátomos a la estabilización del electrón desapareado. La lisina, por su parte, es el aminoácido típico que se presenta como reaccionante con los productos secundarios de oxidación lipídica.

\subsection{A través de reacciones no radicalarias}

Las reacciones no radicalarias tienen lugar entre las proteínas y los productos secundarios de la oxidación lipídica. Este término genérico de productos secundarios de oxidación lipídica engloba a aldehídos, epóxidos, cetonas y toda la serie de productos de descomposición y transformación de los hidroperóxidos lipídicos que fueron descritos en la parte I de este estudio. Algunos de estos productos secundarios reaccionan con los aminoácidos o las proteínas aunque es difícil de determinar la importancia relativa de los productos secundarios respecto de los primarios. Hay algunos estudios comparativos que se recogen en la bibliografía sobre su distinta importancia pero sus resultados son difícilmente interpretables ya que a menudo tanto productos primarios como secundarios producen resultados análogos (15) (39-41).

Existe una evidente desigualdad en la bibliografía en 
el tratamiento que han recibido los diferentes productos secundarios en su interacción con las proteínas. Así mientras el malondialdehído o los aldehídos alifáticos han sido ampliamente estudiados, otros muchos compuestos apenas han sido considerados siendo éste un campo cuyo desarrollo puede aclarar la importancia real que tiene la presencia de malondialdehído en alimentos, cuyas consecuencias, y a la vista de los diferentes resultados encontrados en estos últimos años, puede haber sido magnificada.

El malondialdehído (MDA) ha sido durante mucho tiempo reconocido como uno de los productos secundarios de la oxidación lipídica y su detección con el ácido 2-tiobarbitúrico es la base de un test para oxidación lipídica que ha sido, y sigue siendo en la actualidad, ampliamente utilizado. El grupo de Holman (42) demostró que el MDA era producido a partir del ácido linolénico por un mecanismo que Pryor et al. (43) sugirieron que ocurría a través de los endoperóxidos tipo prostaglandinas descritas en la parte I. Otros autores han encontrado MDA en muestras de ácidos grasos con menos de tres dobles enlaces pero siempre en muy pequeña cantidad y sin un origen muy claro (44) (45).

A causa de su bifuncionalidad, el MDA puede provocar entrecruzamiento en las proteínas. Andrews et al. (46) demostraron en 1965 que mezclas de gelatina y linoleato de metilo peroxidado provocaban el entrecruzamiento en la gelatina. Este entrecruzamiento fue definido por Chio y Tappel (47) como una base de Schiff conjugada (Figura 1a). Esta base de Schiff es un cromóforo fluorescente con máximo de excitación a $\sim 370 \mathrm{~nm}$ y máximo de emisión a $\sim 450 \mathrm{~nm}$. La fluorescencia fue demostrada en la polimerización inducida por el MDA de la ribonucleasa $A$ (48).

$$
\text { A. }
$$

$$
\mathrm{RNH}-\mathrm{CH}=\mathrm{CH}-\mathrm{CH}=\mathrm{NR}
$$

BASES DE SCHIFF CONJUGADAS

B.

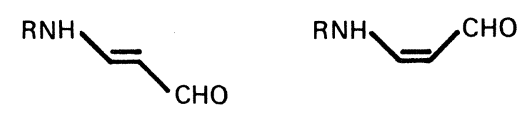

ENAMINALES

C.<smiles>CC1C(C=O)=CNC=C1C=O</smiles><smiles>CCCCc1c[nH]cc1C=O</smiles>

DIHIDROPIRIDINAS

Figura 1

Productos aislados en la reacción entre malondialdehído y aminas.
Desde el descubrimiento de esta fluorescencia inducida por el MDA, se ha producido un considerable interés en este campo, especialmente por parte del grupo de Tappel en Davis (49), quiénes frecuentemente han correlacionado la fluorescencia inducida por el MDA con una fluorescencia similar en pigmentos que se acumulan con el envejecimiento (habitualmente conocidos como lipofuscinas). De acuerdo con Tappel, estos pigmentos de tipo lipofuscina podrían acumularse en un organismo con la edad debido a la peroxidación lipídica in vivo, y la fluorescencia observada sería debida a bases de Schiff.

Aunque Malshet y Tappel (50) han propuesto que el cromóforo fluorescente era producido exclusivamente por el MDA y no por otros compuestos carbonílicos derivados de los hidroperóxidos lipídicos, hoy en día hay datos que ponen en duda tal afirmación.

El grupo de Kikugawa en Tokyo ha estudiado la reacción de malondialdehído con aminas primarias y aminoácidos bajo condiciones fisiológicas y ha obtenido otros tipos de compuestos altamente fluorescentes, que se recogen en la Figura 1 (51-55). El espectro de fluorescencia de las dihidropiridinas, que también se obtienen en la reacción entre MDA y proteínas en presencia y/o ausencia de aminas primarias, presenta un máximo de excitación aproximadamente a $400 \mathrm{~nm}$ y un máximo de emisión aproximadamente a $470 \mathrm{~nm}$. Estas características son análogas a las de la estructura de Tappel que ellos dudan que sea fluorescente porque al preparar bases de Schiff conjugadas, análogas a las de Tappel pero con aminas aromáticas, encontraron que éstas no eran fluorescentes (56).

- Cualquiera que sea la estructura, cuando una muestra de polilisina se trata con 13-hidroperóxido del ácido linoleico o con aldehídos mono o bifuncionales se obtienen estructuras fluorescentes cuyas características difieren de las obtenidas con MDA (57). Esta diferencia es tanto en los máximos de fluorescencia como en la intensidad o el decrecimiento que experimenta la misma con el tratamiento con borohidruro sódico. La fluorescencia que presenta la reacción del hidroperóxido del ácido linoleico, cuya descomposición no produce MDA, es análoga a la de los aldehídos alifáticos monofuncionales de cadena corta y no a la reacción con MDA. Esto sugiere la formación de diversas estructuras fluorescentes que es dependiente del tipo de productos secundarios que produzca la degradación del lípido oxidado y, de alguna manera, indica que los aldehídos alifáticos monofuncionales pueden jugar un papel análogo al MDA.

Estos aldehídos simples, que son conocidos desde antiguo como formadores de bases de Schiff con los grupos aminos libres de las proteínas, no habían sido considerados, sin embargo, capaces de inducir fluorescencia y polimerización en las proteínas. Nuestro grupo ha encontrado que sí lo son (véase, por ejemplo ref. 30 y 41) y quizás por un mecanismo análogo al de la Figura 2. Una prueba que apoya este mecanismo es que en el caso de que tras la reacción con el primer grupo amino, la segunda reacción sea intramolecular sobre el mismo, entonces el proceso evolucionaría a una estructura cíclica del tipo que se recoge en la Figura 3. Estas sales de 
piridinio han sido recogidas en la literatura y están entre los principales productos de la reacción entre aminas y aldehídos alifáticos (58) (59). Nuestro grupo (30) ha encontrado que, en la reacción entre la B-lactoglobulina y el 13-LOOH, fluorescencia y polimerización estaban relacionados. Si esto es así habría que estudiar si alguna de las estructuras hipotéticas que se proponen en la Figura 2 es fluorescente. La sal de piridinio de la Figura 3 no lo es, pero la pérdida de fluorescencia podría ser debida a la carga positiva que soporta el nitrógeno heterocíclico.
Aunque la formación de estructuras fluorescentes ha recibido una gran atención en la literatura, indudablemente por la facilidad que existe para detectarla y porque puede servir como un buen indicador que muestre el deterioro de las proteínas, la verdad es que la importancia real que la formación de estas estructuras tiene sobre el valor nutritivo o el deterioro de las proteínas es muy inferior a lo que pudiera pensarse. Cuando el grupo de Kikugawa estudió la reacción entre la polilisina y el MDA (57) encontró que tras $22 \mathrm{~h}$ de reacción la formación del fluoróóo-

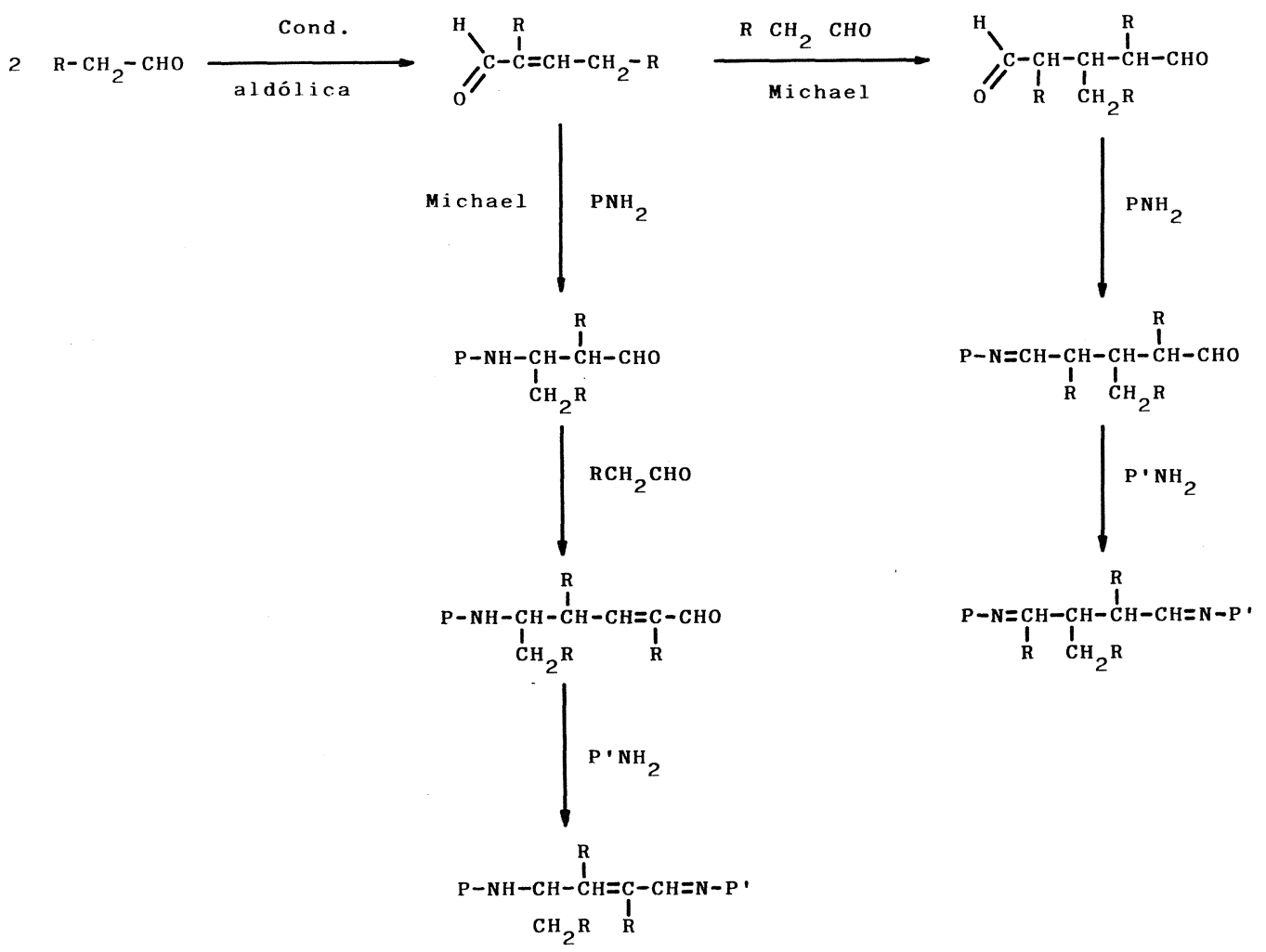

Figura 2

Mecanismo propuesto para la polimerización de proteínas con aldehídos monofuncionales.

ro implicaba menos del $0,2 \%$ de los grupos amino de la proteína mientras que en el mismo tiempo un $22 \%$ de los mismos grupos habian sido modificados por formación de estructuras no fluorescentes. Esto nos lleva a considerar la importancia que la formación de estas estructuras no fluorescentes pudieran tener.

Las reacciones de oscurecimiento no enzimático han sido reconocidas durante mucho tiempo como una consecuencia de la peroxidación de lípidos en presencia de proteínas. Esto, por ejemplo, es lo que ocurre en el pescado a causa de la presencia de lípidos altamente insaturados. De acuerdo al grupo de Pokorny, este oscurecimiento es afectado por parámetros tales como los grupos aminos libres (60), el grado de peroxidación (61) (62), y la insaturación lipídica (63). Desde que ya en el año 1949 se descubrió (64) que el acetaldehído causaba el oscurecimiento de las proteínas se ha reconocido que las bases de Schiff conducen a estos pigmentos oscuros. Este oscurecimiento, que ocurre más rápidamente con aldehídos $\alpha, \beta$-insaturados que con los aldehídos saturados (65), se interpreta como policondensaciones aldólicas de aldehídos con bases de Schiff (66-69). Las sucesivas condensaciones aldólicas extienden el cromóforo conjugado y eventualmente el grupo amino se puede incluso escindir del polímero. Por estas razones el contenido de nitrógeno en estos pigmentos puede variar dentro de un rango de valores bastante amplio aunque en general suele ser pequeño (60) (69).

Frecuentemente en este tipo de reacciones de oscurecimiento se produce simultáneamente la liberación de aldehídos (5). Estos productos de la oxidación lipídica son usualmente volátiles y emanan olores potentes. No obstante, en las reacciones de oscurecimiento se ha observado que los mismos producen olores a goma (70) y a aromas de pescados (71) que no son los característicos de los olores aldehídicos. De una mezcla de heptanal y el éster etílico de la tirosina. Montgomery y Day aislaron 2-alquenales (66). Ellos sugirieron que la formación del 


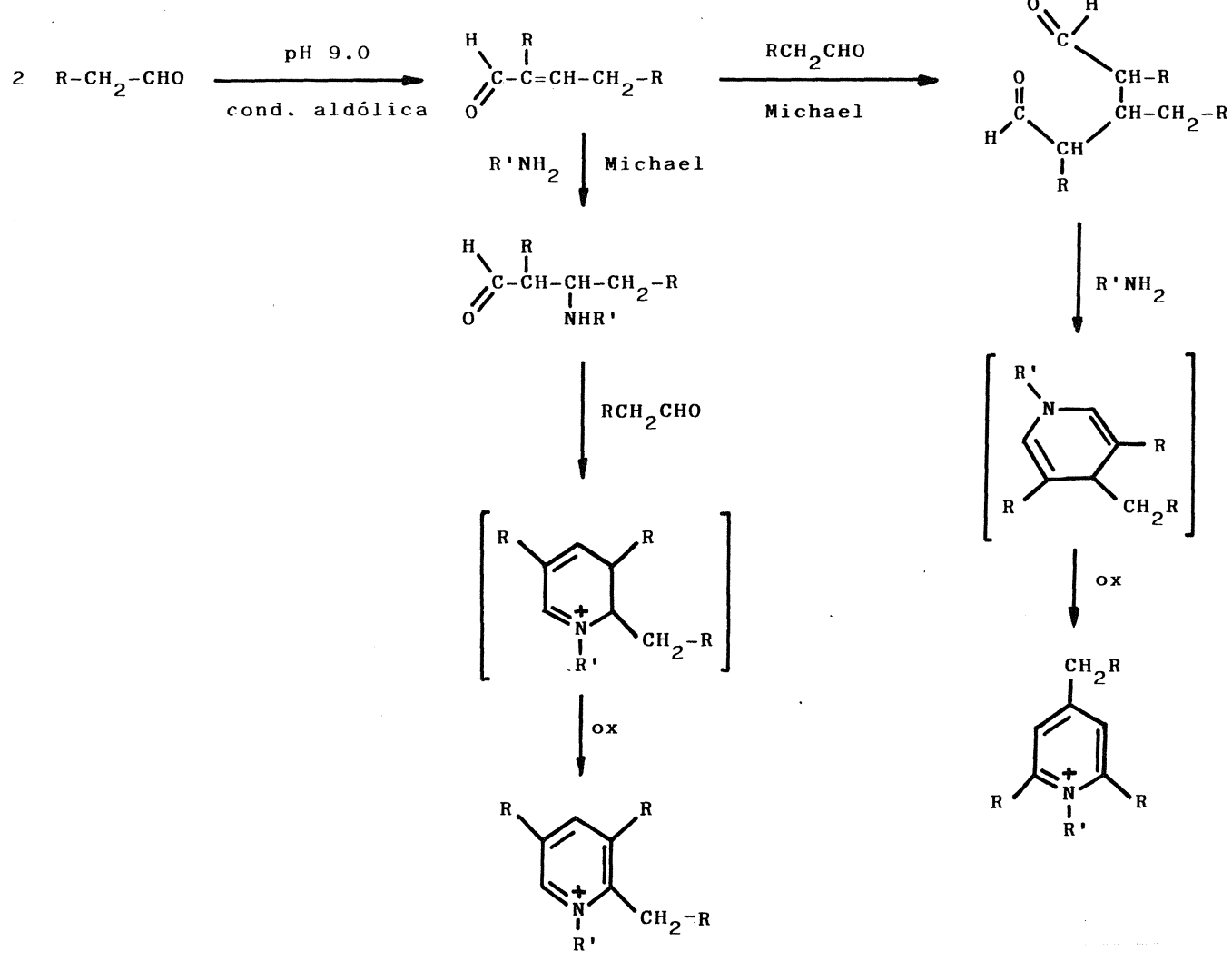

Figura 3

Mecanismo propuesto para la formación de sales de piridinio entre aldehídos monofuncionales y compuestos aminados.

2-alquenal es consistente con la regeneración del aminoácido a partir del producto de condensación aldólica. Este hecho ha sido encontrado también por otros autores (69) aunque parecer ser que tales reacciones pueden ocurrir también en ausencia del aminoácido.

Los aldehídos no reaccionan exclusivamente con los grupos amino de las proteínas aunque estas reacciones han sido, con mucho, las más estudiadas. De acuerdo con Esterbauer (72) las reacciones con tirosina, triptófano e histidina transcurren con participación del grupo amino de los aminoácidos por lo que en una proteína no parece que vayan a tener mucha importancia. Sin embargo, la reacción con la cisteína que, cuando se lleva a cabo con un aldehído saturado transcurre de manera análoga a la de los otros aminoácidos, cuando se lleva a cabo con un aldehído $\alpha, \beta$-insaturado o con un 4-hidroxi-2-alquenal produce la adición del aminoácido al aldehído en un primer paso para terminar en la tiazolidina habitual (73). Esta reacción sí pudiera tener algún efecto en las proteínas alimenticias aunque en la mayoría de los casos el grupo sulfhidrilo va a ser degradado por los lípidos peroxidantes antes de que pudieran reaccionar con los aldehídos producidos en la degradación lipídica.

Los volátiles en general, y los aldehídos en particular, son los compuestos que han acaparado casi todo el esfuerzo que se ha realizado en el esclarecimiento de este tipo de interacciones. No obstante, ellos sólo representan el $10-15 \%$ de los productos de oxidación lipídica, lo que quiere decir que puede haber una enorme variedad de reacciones de las que apenas podemos intuir cómo tienen lugar y qué efectos pueden producir.

Cuando el grupo de Gardner llevó a cabo el estudio de la reacción entre el hidroperóxido del ácido linoleico y la cisteína encontraron una tiazolidina que debía provenir del ácido 4-oxo-nonanoico producido por una escisión de la cadena del ácido graso (32). Esto puede ser una prueba de cómo los hidroxi, ceto y epoxiderivados de la oxidación lipídica pueden jugar un papel en la degradación de las proteínas.

Hay pocos ejemplos más.

El grupo de Pokorny estudió la reacción del ácido 10-oxo-9-hidroxiesteárico y 9-oxo-10-hidroxiesteárico con albúmina (74) y obtuvieron una reacción de oscurecimiento. Ellos encontraron posteriormente (67) que el ácido oxohidroxiesteárico podía enlazar dos grupos amino pero la estructura específica no fue determinada.

La reacción del ácido 12-cetooleico con aminas y aminoácidos sin grupo tiol produjo sustancias fluorescentes con máximo de excitación a $345 \mathrm{~nm}$ y máximo de emisión a $400 \mathrm{~nm}(75)$, cuyas estructuras han sido determinadas (76). Los autores atribuyeron la fluorescencia al sistema de enaminona del producto. Este sistema ha sido estudiado por nosotros y no presenta fluorescencia ( $\mathrm{Za}$ mora et al., resultados sin publicar).

El hecho de que el desarrollo de la fluorescencia se inhiba en presencia de aminoácidos azufrados puede ser debido a que el grupo sulfhidrilo compite con el grupo 
amino impidiendo la reacción. Este hecho ha sido observado por nuestro grupo (77) cuando estudiamos la reacción entre el 12-cetooleico y el glutatión. En este caso la fluorescencia de la reacción fue muy pequeña, muy distinto a cuando la reacción se llevó a cabo con el ácido 13-ceto-9,11-octadecadienoico donde obtuvimos una importante fluorescencia. Nosotros atribuimos este hecho a la existencia de una conjugación entre el grupo carbonílico y los dobles enlaces. La estructura del compuesto fluorescente no ha podido ser determinada aún pero hay datos que permiten afirmar que la cadena del cetoácido no sufrió fraccionamiento (77).

Otros importantes productos de la oxidación lipídica son los epóxidos lipídicos. Ya en 1966 el grupo de Pokorny observó el enlace del ácido 9, 10-epoxiesteárico a albúmina (78). La estructura no fue determinada pero se puede suponer que debe estar relacionada con una sustitución nucleofílica que implica la apertura del anillo de epoxi.

Finalmente, el ácido 9-oxo-trans-12,13-epoxitrans-10-octadecenoico, que es un producto importante de la degradación homolítica del hidroperóxido del ácido linoleico (79) y que se acumula en los homogenizados de soja durante la peroxidación del ácido linoleico (80), se ha visto que reacciona con la glicina produciendo diferentes compuestos que todavía no han sido caracterizados (5).

\section{AGRADECIMIENTO}

Al Prof. Eduardo Vioque por sus valiosas discusiones durante la realización de este trabajo.

\section{BIBLIOGRAFIA}

1. Hidalgo, F.J.; Zamora, R. y Alaiz, M.- "Modificaciones producidas en las proteina alimentarias por su interacción con lípidos peroxidados. I. Química radicalaria de los ácidos grasos poliinsaturados".- Grasas y Aceites 42 (1991) 379-386.

2. Pokorny, J. Davidek, J: Chi, TH: Valentova, $\mathrm{H}$; Matejicek, J y Dlaskova, Z.- "Reactions of oxidized lipids with protein. Part 15 Mechanism of lipoprotein formation from interactions of oxidized ethyl linoleate with egg albumin".- Nahrung 32 (1988) 343-350.

3. Nielsen, H.K.; Loliger, J. y Hurrell, R.F.- "Reactions of protein with oxidizing lipids. I. Analytical measurements of lipid oxidation and amino acid losses in a whey protein-methyl linolenate model system".- $\mathrm{Br}$. J. Nutr. 53 (1985) 61-73.

4. Mauron, J.- "Proc. XIII Int. Congress Nutr".- Taylor, T.G. y Jenkins, N.K. (Eds.) John Libbey and Company, Ltd. London, 1986.

5. Gardner, H.W.- "Lipid hydroperoxide reactivity with proteins and amino acids: a review".- J. Agric. Food Chem. 27 (1979) 220-229.

6. Narayan, K.A. y Kummerow, F.A.- "Oxidized fatty acid-protein complex".- J. Am. Oil Chemists' Soc. 35 (1958) 52-56.

7. Narayan, K.A. y Kummerow, F.A.- "Factors influencing the formation of complexes between oxidizing lipids and proteins".- J. Am. Oil. Chemists' Soc. 40 (1963) 339-342.

8. Narayan, K.A.: Sugai, M. y Kummerow, F.A.- "Complex formation between oxidized lipids and egg albumin".- J. Am. Oil Chemists' Soc. 41 (1964) 254-259.

9. Damoradan, S y Kinsella, J.E.- "Flavor protein interactions. Binding of carbonyls to bovine serum albumin: Thermodynamic and conformational effects".- J. Agric. Food Chem. 28 (1980) 567-571.
10. Damodaran, S. y Kinsella, J.E.- "Interaction of carbonyls with soy proteins: Thermodynamic effects".- J. Agric. Food Chem. 29 (1981) 1249-1253.

11. Damodaran, S. y Kinsella, J.E.- "Interaction of carbonyls with soy proteins: Conformational effects".- J. Agric. Food Chem. 29 (1981) 1253-1257.

12. Pokorny, J.- "Über die Bildung von Komplexverbindungen bei der Reaktion oxydieter Lipids mit Eiweißstoffen".- Fette Seifen Anstrichm. 65 (1963) 278-284.

13. Pokorny, J.; Janicek, G. y Davidek, J.- "Determination of the interaction products of protein with lipids".- Zesz. Probl. Postepow Nauk Roln. 167 (1975) 155-170.

14. Pokorny, J.; Kocourek, V. y Zajic, J.- "Reactions of oxidized lipids with protein. Part XII, Interactions of polar groups of lipids with nonlipidic substances".- Nahrung 20 (1976) 707-714.

15. Kanazawa, K.; Danno, G. y Natake, M.- "Lysozyme damage caused by secondary degradation products during the autoxidation process of linoleic acid".- J. Nutr. Sci. Vitaminol. 21 (1975) 373-382.

16. Matsushita, S.; Kobayashi, M. y Nitta, Y.- "Inactivation of enzyme by linoleic acid hidroperoxides and linoleic acid".- Agric. Biol. Chem. 34 (1970) 817-824

17. Matsushita, S. y Kobayashi, M.- "Effects of linoleic acid hydroperoxides on pepsin activity".- Agric. Biol. Chem. 34 (1970) 825-829.

18. Sessa, D.J. y Rackis, J.J.- "Lipid-derived flavors of legume protein products".- J. Am. Oil Chemists' Soc. 54 (1977) 468-473.

19. Eriksson, C.E.; Lundgren, B. y Vallentin, K.- "Odor detectability of aldehydes and alcohols originating from lipid oxidation".- Chem. Senses Flavor 2 (1976) 3-15.

20. Frazen, K.L. y Kinsella, J.E.- "Parameters affecting the binding of volatile flavor compounds in model food systems. I. Proteins".- J. Agric. Food Chem. 22 (1974) 675-678.

21. Beyeler, M. y Solms, J.- "Interaction of flavor model compounds with soy protein and bovine serum albumin".- Lebensm.- Wiss. Technol. 7 (1974) 217-219.

22. Gardner, H.W.- "Effects of lipids hydroperoxides on food components" en "Xenobiotics in food and feeds", pp. 63-84.- Finley, J.W. y Schwass, D.E. (Eds.), A.C.S. Symp. Serie 234. American Chemical Society, Washington D.C., 1983

23. Schaich, K. y Karel, M.- "Free radical reactions of peroxidizing lipid with amino acids and proteins: An ESR study".- Lipids 11 (1976) 392-400.

24. Zirlin, A. y Karel, M.- "Oxidation effects in a freeze-dried gelatin-methyl linoleate system".- J. Food Sci. 34 (1969) 160-164.

25. Lewis, S.E. y Wills, E.D.- "Destruction of sulfhydryl groups of proteins and amino acids by peroxides of unsaturated fatty acids".-Biochem Pharmacol. 11 (1962) 901-912.

26. Roubal, W.T. y Tappel, A.L.- "Damage to proteins, enzymes and amino acids by peroxidizing lipids".- Arch. Biochem. Biophys. 113 (1966) 5-8.

27. Gardner, H.W. y Jursinic, P.A.- "Degradation of linoleic acid hydroperoxide by a cysteine. $\mathrm{FeCl}_{3}$ catalyst as a model for simila biochemical reactions. I. Study of oxygen requirement, catalyst and effect of pH".- Biochim. Biophys. Acta 665 (1985) 100-112.

28. Finley, J.W.; Wheeler, E.L. y Witt, S.C.- "Oxidation of glutathione by hydrogen peroxide and other oxidizing agents".- J. Agric. Food Chem. 29 (1981) 404-407.

29. Finley, J.W. y Lundin, R.E.- "Lipid hydroperoxide induced oxidation of cysteine in peptides" en "Autoxidation in Food and Biological Systems", pp. 223-235.- Simic, M.G. y Karel, M. (Eds.), Plenum Press, New York, 1980.

30. Hidalgo, F.J. y Kinsella, J.E.- "Changes induced in B-lactoglobulin B following interaction with linoleic acid 13-hydroperoxide".- J. Agric. Food Chem. 37 (1989) 860-866.

31. Gardner, H.W. Weisleder, D. y Kleiman, R.- "Addition of $\mathrm{N}$-acetylcysteine to linoleic acid hydroperoxide".- Lipids 11 (1976) 127-134.

32. Gardner, H.W.; Kleiman, R.; Weisleder, D. y Inglet, G.E.- "Cysteine adds to lipid hydroperoxide".- Lipids 12 (1977) 655-660.

33. Karel, M.: Schaich, K. y Boy, R.B.- "Interaction of peroxidizing methy linoleate with some proteins and amino acids".- J. Agric. Food Chem. 23 (1975) 159-163. 
34. Njaa, L.R.; Utne, F. y Braekkan, O.R.- "Antioxidant properties of methionine esters".- Nature 218 (1968) 571-572.

35. Yong, S.H.; Lau, S.; Hsieh, Y. y Karel, M.- "Degradation products of L-tryptophan reacted with peroxidizing methyl linoleate" en "Autoxidation in Food and Biological Systems", pp. 237-247.- Simic M.G. y Karel, M. (Eds.) Plenum Press, New York, 1980.

36. Sundberg, R.J.- Chemistry of Indoles.- Academic Press, New York, 1980.

37. Saito, I.; Imuta, M.; Nakada, A.; Matsugo, S. y Matsuura, T.- "Peroxidic intermediates in indole-singlet oxygen reactions: mechanism of the C2-C3 ring cleavage of tryptophol".- Photochem. Photobiol. 28 (1978) 531-534.

38. Neukom, H.- "Oxidative crosslinking of proteins and other biopolymers" en "Autoxidation in Food and Biological Systems", pp. 249-259.- Simic, M.G. y Karel, M. (Eds.), Plenum Press, New York, 1980.

39. Gamage, P.T. y Matsushita, S.- "Interactions of the autoxidized products of linoleic acid with enzyme proteins".- Agric. Biol. Chem. 37 (1973) 1-8.

40. Matsushita, S.- "Specific interactions of linoleic acid hydroperoxides and their secondary degraded products with enzyme proteins".- $J$ Agric. Food Chem. 23 (1975) 150-154.

41. Zamora, R.; Millán, F.; Hidalgo, F.J.: Alaiz, M.; Maza, M.P.; Olias J.M. y Vioque, E.- "Interaction between the peptide glutathione and linoleic acid hydroperoxide".- Nahrung 33 (1989) 283-288.

42. Dahle, L.K.; Hill, E.G. y Holman, R.T.- "The thiobarbituric acid reactions and the autoxidation of polyunsaturated fatty acid methyl esters". Arch. Biochem. Biophys. 98 (1962) 253-261.

43. Pryor, W.A.; Stanley, J.P. y Blair, E.- "Autoxidation of polyunsaturated fatty acids: II. A suggested mechanism for the formation of TBA-reactive materials from prostaglandin-like endoperoxides".- Lipids 11 (1976) 370-379.

44. Tarladgis, B.G. y Watts, B.M.- "Malonaldehyde production during the controlled oxidation of pure unsaturated fatty acids".- J. Am. Oil. Chemists' Soc. 37 (1960) 403-406.

45. Frankel, E.N.- "Biological significance of secondary lipid oxidation products".- Free Radical Res. Commun. 3 (1987) 213-225.

46. Andrews, F.; Bjorksten, J.; Trenk, F.B.; Henick, A.S. y Koch, R.B."The reaction of an autoxidized lipid with proteins".- J. Am. Oil Chemists'Soc. 42 (1965) 779-781.

47. Chio, K.S. y Tappel, A.L.- "Synthesis and characterization of the fluorescent products derived from malondialdehyde and amino acids". Biochemistry 8 (1969) 2821-2827.

48. Chio, K.S. y Tappel, A.L.- "Inactivation of ribonuclease and other enzymes by peroxidizing lipids and by malondialdehyde".- Biochemistry 8 (1969) 2827-2832

49. Tappel, A.L.- "Lipid peroxidation damage to cell components".- Fed. Proc. Fed. Am. Soc. Exp. Biol. 32 (1973) 1870-1874.

50. Malshet, V.G. y Tappel, A.L.- "Fluorescent products of lipid peroxidation: I. Structural requerement for fluorescent in conjugated Schiff bases".- Lipids 8 (1973) 194-198

51. Kikugawa, K.; Maruyama, T.; Machida, Y. y Kurechi, T.- "Studies on peroxidized lipids. II. Fluorescent products relevant to aging pigments derived from malonaldehyde and methylamine".- Chem. Pharm. Bull. 29 (1981) 1423-1432.

52. Kikugawa, K.; Machida, T.; Kida, M. y Kurechi, T.- "Studies on peroxidized lipids. III. Fluorescent pigments derived from the reaction of malondialdehyde and amino acids".- Chem. Pharm. Bull. 29 (1981) 3003-3011.

53. Kikugawa, K. y Ido, Y.- "Studies on peroxidized lipids. V. Formation and characterization of 1,4-dihydropyridines-3,5-dicarbaldehydes as model of fluorescent components in lipofuscin".- Lipids 19 (1984) 600-608.

54. Kikugawa, K.; Ido, Y. y Makami, A.- "Studies on peroxided lipids. VI Fluorescent products derived from the reaction of primary amines malonaldehyde and monofunctional aldehydes".- J. Am. Oil Chemists Soc. 61 (1984) 1574-1581.

55. Kikugawa, K. y Beppu, M.- "Involvement of lipid oxidation products in the formation of fluorescent and cross-linked proteins".- Chem. Phys. Lipids 44 (1987) 277-296.

56. Kikugawa, K. y Sugimura, Y.- "Properties of conjugated Schiff bases of malondialdehyde".- Chem. Pharm. Bull. 34 (1986) 1794-1800.

57. Kikugawa, K.; Takayanagi, K. y Watanabe, S.- "Polylysines modified with malonaldehyde, hydroperoxylinoleic acid and monofunctional aldehydes".- Chem. Pharm. Bull. 33 (1985) 5437-5444.
58. Suyama, K. y Adachi, S.- "Reaction of alkanals and amino acids or primary amines. Synthesis of 1, 2, 3, 5- and 1, 3, 4, 5-substituted quaternary pyridinium salts".- J. Org. Chem. 44 (1979) 1417-1420.

59. Suyama, K. y Adachi, S.- "Quanternary pyridinium salts formed by amino-carbonyl reaction and other thermal elimination reaction involving carbocation formation" en "Amino-Carbonyl Reactions in Food and Biological Systems", pp. 95-103.- Fujimaki, M.; Namiki, M. y Kato, H. (Eds.), Developments in Food Science. Vol. 13. Elservier, Tokyo 1986.

60. Pokorny, J.; Kolakowska, A.; El-Zeany, B.A. y Janicek, G. "Nonenzymic browning. XI. Effect of free amino groups on browning reactions in lipid-protein mixtures".- Z. Lebensm.- Unters. Forsch. 157 (1975) 323-326.

61. Pokorny, J.; El-Zeany, B.A. y Janicek, G.- "Nonezymic browning. VI. Browning produced by oxidized polyunsaturated lipids on storage with protein in the presence of water".- Z. Lebensm.- Unters. Forsch. 151 (1973) 157-161.

62. Pokorny, J.; El-Zeany, B.A.; Kolakowska, A. y Janicek, G. "Nonenzymic browning. IX. Correlation of autoxidation and browning reactions in lipid-protein mixtures".- Z. Lebensm.- Unters. Forsch. 155 (1974) 287-291.

63. Pokorny, J.; El-Zeany, B.A.; Luan, N.T. y Janicek, G.- "Nonezymic browning. XV. Effects of unsaturation on browning reactions of oxidized lipids with protein".- Z. Lebensm. Unters. Forsch. 161 (1976) 271-272.

64. Mohammad, A.; Olcott, H.S. y Fraenkel-Conrat, H.- "Reaction of protein with acetaldehyde".- Arch. Biochem. 24 (1949) 270-280.

65. Burton, H.S. y McWeeny, D.J.- "Nonenzymic browning: routes to the production of melanoidins from aldoses and amino compounds". Chem. Ind. (1964) 462-463.

66. Montgomery, M.W. y Day, E.A.- "Aldehyde-amine condesation reaction: a possible fate of carbonyls in food".- J. Food Sci. 30 (1965) 828-832.

67. Janicek, G. y Pokorny, J.- "Nonenzymic browning. I. Reactions of aliphatic carbonyl derivatives with amines in model systems".- Z Lebensm.- Unters. Forsch. 145 (1971) 142-147.

68. Tai, P.T.; Pokorny, J. y Janicek, G.- "Nonenzymic browning. X. Kinetics of oxidative browning of phosphatidylethanolamine".- Z. Lebensm. Unters Forsch. 156 (1974) 257-262.

69. Davidek, J. y Jirousova, J.- "Formation of volatile compounds and brown products in the model system $n$-hexanal-glycine".- Z. Lebensm. Unters. Forsch. 159 (1975) 153-159.

70. Pokorny, J.; Luan, N.T.; Kondratenko, S.S. y Janicek, G.- "Changes of sensory value by interaction of alkanals with amino acids and proteins".- Nahrung 20 (1976) 267-272.

71. Pokorny, J.; Luan, N.T.; El-Zeany, B.A. y Janicek, G.- "Bildung von Fischaroma durch Reaktion autoxydierter Lipide mit Aminosäuren und Proteinen".- Nahrung 20 (1976) 273-279.

72. Esterbauer, H.- "Aldehydic products of lipid peroxidation" en "Free Radicals, Lipid Peroxidation and Cancer". pp. 101-128.- McBien, D.C.H. y Slater, T.F. (Eds.), Academic Press, London 1982.

73. Esterbauer, H.; Ertl, A. y Scholz, N.- "The reaction of cysteine with $\alpha$, B-unsaturated aldehydes".- Tetrahedron 32 (1976) 285-289.

74. Pokorny, J.; Klein, S. y Zelinkova, M.- "Reaktionen oxydierter Lipide mit Eiweißstoffen. 3. Mitt Reaktion von Albumin mit Hydroxyketostearinsäuren".- Nahrung 11 (1967) 121-128.

75. Fukuzawa, K. y Sato, M.- "Accelerating effects of 12-keto oleic acid on lipid peroxide and fluorescent productions in mouse live homogenate".- J. Nutr. Sci. Vitaminol. 21 (1975) 79-88.

76. Fukuzawa, K.; Kishikawa, K.; Tokumura, A.; Tsukatami, H. y Shibuya, M.- "Fluorescent pigments by covalent binding of lipid peroxidation by-products to protein and amino acids".- Lipids 20 (1985) 854-861.

77. Zamora, R.; Hidalgo, F.J.; Alaiz, M.; Millán, F.; Maza, M.P. y Vioque E.- "Interacción entre el glutatión y diferentes oxoácidos grasos".Grasas y Aceites 38 (1987) 318-322.

78. Pokorny, J.: Klein, S. y Koren, J.- "Reaktionen oxydieter Lipide mi Eiweißstoffen. 2. Mitt Reaktion von Albumin mit Epoxyderivaten". Nahrung 10 (1966) 321-325.

79. Gardner, H.W.: Kleiman, R. y Weisleder, D.- "Homolytic decomposition of linoleic acid hydroperoxide: Identification of fatty acid products". Lipids 9 (1974) 696-706.

80. Gardner, H.W. y Kleiman, R.- "A soy extract catalyzes formation of 9-oxo-trans-12,13-epoxy-trans-10-octadecenoic acid from 13-hydroperoxy-cis-9, trans-11-octadecadienoic acid".- Lipids 12 (1977) 941-944.

(Recibido: diciembre 1990) 